\title{
HEGEMONI KEKUASAAN PEMANGKU ADAT MINANGKABAU DALAM NOVEL TENGGELAMNYA KAPAL VAN DER WIJCK KARYA HAMKA: KAJIAN HEGEMONI GRAMSCI
}

\section{Nita Kartika Sari ${ }^{\bowtie}$, Sumartini, U’um Qomariyah}

Jurusan Bahasa dan Sastra Indonesia, Fakultas Bahasa dan Seni, Universitas Negeri Semarang, Indonesia

\section{Info Artikel}

Sejarah Artikel:

Diterima Oktober 2017

Disetujui Desember 2017

Dipublikasikan Maret

2018

\section{Keywords:}

hegemony; elders;

Minangkabau culture;

domination

\begin{abstract}
Abstrak
Karya sastra memang tidak bisa dilepaskan begitu saja dari pengarang dan keadaan sosial yang melatarbelakangi penciptaanya serta segala gejolak kemasyarakatan yang ada seperti kekuasaan dan dominasi yang dirasa merugikan. Dari tiga rumusan masalah penulis hanya akan memfokuskan pembahasan pada bentuk hegemoni yang dilakukan pemangku adat di Minangkabau. Metode yang digunakan dalam penelitian ini yaitu metode deskriptif kualitatif. Penelitian ini menggunakan pendekatan sosiologi sastra dan teori hegemoni Antonio Gramsci. Sumber data adalah novel Tenggelamnya Kapal Van Der Wijck karya Hamka. Data diperoleh dengan teknik membaca dan mencatat. Hasil penelitian berupa jenis hegemoni yang disadari dan tidak disadari. Terdapat empat bentuk dari hegemoni yang disadari yaitu kekeraan, penindasan, paksaan dan perampasan, sedangkan bentuk dari hegemoni yang tidak disadari berupa provokasi.
\end{abstract}

\section{Abstract}

There is an inseparable bond between a literary work with the background experience of its writer, and the underlying socio-cultural circumstances behind its creation, as well as all the existing disadvantageous problems in society such as hegemony and dominance. Of the three research problems, the discussion in this article will focus solely on the form of hegemony practices done by the Elders in Minangkabau culture. In conducting this research, descriptive qualitative approach is used. Literary sociological approach using the theory of Hegemony by Antonio Gramsci is used as the research approach. The data are obtained by using reading and noting technique. The data source is the novel Tenggelamnya Kapal Van der Wijck by Hamka. As the result of the research, there are two type of hegemony practices found, the conscious and unconscious hegemony. The conscious hegemony take four forms, there are: violence, oppression, coercion and deprivation. Meanwhile the unconscious hegemony realized only in form of provocation.

(C) 2018 Universitas Negeri Semarang

\footnotetext{
Alamat korespondensi:

Gedung B1 Lantai 1 FBS Unnes

Kampus Sekaran, Gunungpati, Semarang, 50229

E-mail: vusufsvaifulamin@gmail.com
}

ISSN 2252-6315 


\section{PENDAHULUAN}

Sastra bisa dikatakan sebagai karya kreatif yang menggunakan manusia dan kehidupannya sebagai objek. Karya sastra yang lahir di tengahtengah masyarakat merupakan sebuah hasil imajinasi dan refleksi terhadap gejala-gejala sosial yang ada di sekitar lingkungan pengarang. Dengan kata lain, karya sastra tersebut merupakan hasil dari serangkaian proses perenungan dan pengalaman pengarang dalam menghadapi dan menyelami nilai-nilai tentang kehidupan.Hal ini menunjukan bahwa persoalan sosial sangat berpengaruh kuat terhadap wujud karya sastra.

Hal ini sesuai dengan pendapat Pradopo (1994: 59) yang menyatakan bahwa karya sastra secara langsung dan tidak langsung dipengaruhi oleh pengalaman dari lingkungan pengarang. Karya sastra menerima pengaruh dari masyarakat dan sekaligus mampu memberi pengaruh terhadap masyarakat. Pada kenyataanya karya sastra sastra tidak hanya memberikan kenikmatan, dan kepuasan batin semata. Lebih dalam karya sastra dapat dipahami dan dimanfaatkan bukan hanya untuk pengarang namun masyarakat pembaca.

Karya sastra yang berhubungan dengan keadaan sosial masyarakat ataupun unsur-unsur sosial dalam masyarakat dapat dipahami melalui kajian sosiologi sastra. Kajian ini merupakan sebuah pendekatan terhadap sastra yang mempertimbangkan segi-segi kemasyarakatan serta dapat dipahami sebagai telaah yang objektif dan imanjinatif tentang manusia dalam masyarakat; telaah tentang lembaga dan proses sosial. Sosiologi mencari tahu bagaimana masyarakat dimungkinkan, bagaimana ia berlangsung dan bagaimana ia tetap ada. Dengan mempelajari lembaga-lembaga sosial, dan segala masalah perekonomian, keagaamaan, politik, dan lainnya (Damono, 2010:9)

Karya sastra yang berhubungan dengan manusia kolektif merupakan sesuatu yang dapat dikaji dengan sosiologi sastra. Antonio Gramsci merupakan salah satu tokoh dalam teori sosiologi sastra yang dikenal dengan pemikirannya mengenai hegemoni. Hegemoni berdasarkan pemikiran Gramsci dapat diartikan sebagai suatu kekuasaan atau dominasi atas nilai-nilai kehidupan, norma, maupun kebudayaan sekelompok masyarakat yang akhirnya berubah menjadi doktrin terhadap kelompok masyarakat lainnya, sehingga kelompok yang didominasi tersebut secara sadar mengikutinya (Anwar, 2010: 83).

Melalui karya-karya Hamka pembaca menyadari bahwa dalam sebuah karya sastra perlu adanya penggambaran mengenai kondisi masyarakat pada waktu karya sastra tersebut diciptakan. Karya sastra tidak semata-mata berasal dari sebuah imajinasi pengarang belaka, namun harus memiliki nilai sejarah di dalamnya. Sejarah yang dimaksudkan bisa berupa sejarah yang dihasilkan oleh masyarakat seperti, kebudayaan, tradisi, kepercayaan, dan lainnya sebagai cerminan pada masa karya sastra tersebut diciptakan.

Novel Tenggelamnya Kapal Van Der Wijck bukan satu-satunya karya Hamka yang memiliki latar belakang agama, sosial, dan budaya di dalamnya. Novel ini dipilih oleh penulis sebagai objek penelitian skripsi karena selain belum adanya penelitian yang mengkaji novel Tenggelamnya Kapal Van Der Wijck dengan menggunakan teori hegemoni Gramsci, novel ini berusaha menggambarkan ketimpangan sosial dalam masyarakat Minangkabau yang disebabkan oleh adat, nilai, norma dan kebudayaan di Minangkabau pada saat itu. Adanya adat istiadat yang mendominasi dalam suatu tatanan masyarakat dianggap telah memberikan kekuasaan kepada pemimipin adat untuk menjalankan kekuasaannya. Adanya adat ini tentu memiliki dampak positif dan negatif.

Meskipun novel Tenggelamnya Kapal Van Der Wijck tergolong ke dalam karya sastra lama, namun ternyata masih ada relevansinya dengan masyarakat sekarang. Khususnya bagi masyarakat Minangkabau karena penelitian ini menggunakan teori sosiologi sastra. Selain itu melalui karyanya pengarang berusaha menyampaikan aspirasinya terhadap wujud ketimpangan sosial yang ada di lingkungan tempat tinggal pengarang. 
Guna memperkuat hasil penelitian, penulis melakukan penelusuran terhadap penelitian-penelitian terdahulu yang bertopik linier dengan penelitian yang dilakukan penulis. Dari hasil penelusuran diperoleh beberapa penelitian yang bertopik linier yaitu, Brown (2009) yang berjudul Gramsci and Hegemony yang memfokuskan penelitianya pada gambaran umum teori hegemoni yang dicetuskan oleh Gramsci dan sebab-sebab dibalik formulasinya. Melalui artikel yang dimuat dalam situs http://links.org.au/node/1260,

Brown mencoba mengajak pembaca untuk dapat menelaah lebih jauh mengenai konsep hegemoni, sehingga pembaca atau peneliti dapat meneruskan dan memikirkan cara bagaimana menggunakan konsep-konsep hegemoni secara strategis dalam sebuah perjuangan kelas.

Penelitian yang sama juga dilakukan oleh Schwenz pada tahun 2014. Melalui penelitianya yang berjudul Postcolonial Studies, Hegemony in Gramsci, ia berusaha menggambarkan definisi dan gambaran yang nyata dari hegemoni. Hegemoni secara literasi berarti kepemimpinan, namun pengertian ini ditolak oleh Schwenz. Menurutnya hegemoni baik dalam kajian sosiologi maupun ilmu politik lebih sering dipahami sebagai dominasi dan pengendalian atau kontrol, bukan kepemimpinan. Hegemoni kekuasaan atau pengendalian mengacu pada sistem dominasi suatu etis, dimana elit politik yang berkuasa mengendalikan komunitas etnis yang lebih rendah dengan sedemikian rupa, sehingga bisa mengantisipasi bentuk pemberontakan yang bisa muncul sebagai akibat dari hegemoni tersebut.

Pawestri pada tahun 2015 melakukan penelitian dengan kajian hegemoni yang berjudul Hegemoni Kekuasaan dalam Novel Bibir Merah Karya Achmad Munif yang membahas tentang dominasi kekuasaan yang dilakukan oleh suatu instansi pemerintahan terhadap masyarakat biasa. Fokus penelitian yang dilakukan Prawestri terletak pada formasi idelogi, bentuk hegemoni kekuasaan yang beroperasi dan elemen fiksi yang digunakan untuk merepresentasikan hegemoni kekuasaan dalam novel Bibir Merah karya Achmad Munif.
Penelitian yang sama juga dilakukan oleh Rini pada tahun 2014 dengan judul Hegemoni Mitos Nyai Roro Kidul Terhadap Kekuasaan Jawa dalam Novel Sang Nyai karya Budi Sardjono, memfokuskan penelitian pada hegemoni kekuasaan adat atau budaya jawa atas mitos Nyai Roro Kidul dalam Novel Sang Nyai. Selanjutnya penelitian-penelitian tersebut dijadikan kajian pustaka dalam penelitian yang dilakukan penulis.

\section{METODE PENELITIAN}

Metode yang digunakan dalam penelitian ini adalah metode deskriptif kualitatif. Penelitian ini juga menggunakan teori hegemoni Antonio Gramsci yang merupakan salah satu teori dari pendekatan sosiologi sastra. Teori Hegemoni Gramsci dari pendekatan Sosiologi ini digunakan untuk menujukan adanya dominasi kekuasaan yang terdapat dalam novel Tenggelamnya Kapal Van Der Wijck Karya Hamka.

Data yang dikumpulkan dalam penelitian ini berupa data kualitatif yang berupa kata, frase, kalimat dan paragraf yang memfokuskan pada bentuk hegemoni kekuasaan yang dilakukan oleh pemangku adat di Minangkabau. Sumber data penelitian ini berasal dari novel Tenggelamnya Kapal Van Der Wijck karya Hamka yang diterbitkan oleh penerbit Bulan Bintang pada tahun 1984 dengan ketebalan 224 halaman.

Teknik yang digunakan dalam penelitian ini adalah teknik baca dan catat. . Teknik ini dilakukan dengan cara membaca berulangulang secara cermat dan teliti khusunya pada bagian yang berkaitan dengan hegemoni kekuasaan oleh pemangku adat Minangkabau dalam novel Tenggelamnya Kapal Van Der Wijck kemudian dilanjutkan dengan pencatatan yang sesuai dengan rumusan masalah penulis Selanjutnya data yang terkumpul akan dianalisi menggunakan teknik deskriptif kualitatif, yaitu cara pelukisan data yang mengutamakan penggambarang data melalui kata-kata kemudian disajikan dalam bentuk deskripsi.

\section{HASIL PENELITIAN DAN PEMBAHASAN}

Pada penelitian ini penulis mengunakan novel Tenggelamnya Kapal Van Der Wijck karya 
Hamka untuk menjukkan adanya bentuk hegemoni kekuasaan yang dilakukan oleh pemangku adat di Minangkabau. Dari hasil penelitian terdapat dua jenis hegemoni kekuasaan yang ada dalam novel Tenggelamnya Kapal Van Der Wijck karya Hamka yaitu hegemoni yang disadari dan tidak disadari. Bentuk hegemoni yang disadari berupa adanya kekerasan, penindasan, pekasaan dan perampasan yang dilakukan oleh ninik mamak kepada kemenakkanya dan orang lain. Sedangkan bentuk hegemoni yang tidak disadari berupa adanya provokasi yang bertujuan untuk memrubah pola fikir korban provokasi. Adanya budaya matrilineal dalam masyarakat dirasa telah menjadi faktor utama terbentuknya kelas sosial yang terdiri dari kelas atas dan kelas bawah. Kelas atas terdiri dari para pamangku adat sedangkan kelas bawah terdiri dari para perempuan dan orang-orang yang tidak memiliki ibu yang berasal dari Minangkabau. Hal ini pula yang secara tidak langsung memberikan kekuasaan bagi masyarakat kelas atas untuk mendominasi masyarakat kelas bawah.

\section{Bentuk Hegemoni Kekuasaan dalam Novel Tenggelamnya Kapal Van Der Wijck Karya Hamka}

Berdasarkan pendapat para ahli yang mengacu pada pemikiran Gramsci bahwa suatu kelas menjalankan kekuasaan terhadap kelas dibawahnya dengan cara kekerasan dan persuasi sehingga dari pemikiran itu terdapat dua jenis hegemoni yaitu, hegemoni yang disadari (kekerasan), dan hegemoni yang tidak disadari (persuasi). Hal ini sejalan dengan pendapat Simon yang menyatakan bahwa titik awal Gramsci tentang hegemoni adalah bahwa suatu kelas dan anggotanya menjalankan kekuasaan terhadap kelas-kelas di bawahnya dengan jalan kekerasan dan persuasi (Simon, 2014: 19).

Kedua jenis hegemoni tersebut masingmasing memiliki bentuk hegemoni yang berbeda-beda. Semua bentuk hegemoni yang dilakukan oleh pemangku adat dilakukan secara langsung dan tidak langsung kepada Hayati dan Zainuddin sebagai korban dari hegemoni tersebut. Adapun kedua jenis hegemoni beserta bentuk-bentuk dari masing-masing jenis hegemoni diuraikan dalam sub-sub bab sebagai berikut:

\section{Hegemoni Kekuasaan yang Disadari dalam Novel Tenggelamnya Kapal Van Der Wijck Karya Hamka}

Hegemoni kekuasaan yang disadari memiliki empat bentuk yaitu kekerasan, penindasan, paksaan dan perampasan. Keempat bentuk hegemoni tersebut dilakukan oleh semua pemangku adat (ninik mamak, dan bako) kepada Hayati dan keluarga Zainuddin. Bentukbentuk hegemoni tersebut terjadi secara langsung dan tidak langsung.

\section{a) Kekerasan}

Dalam novel Tenggelamnya Kapal Van Der Wijck karya Hamka semua pemangku adat (ninik mamak) melakukan hegemoni kepada kemenakannya dengan dalil kekuasaan yang diberikan oleh adat. Bentuk hegemoni yang disadari pertama adalah kekerasan yang dilakukan oleh Datuak Mantari Labih kepada Pandekar Sutan (Ayah Zainuddin). Hal ini tertuang dalam kutipan berikut:

„Apa?. engkau katakana saya
zalim?" kata Datuak Mantari
Labih sambil melompat ke muka,
dan menyentak kerisnya, tiba sekali
di hadapan Pendekar Sutan.
Malang akan timbul, sebelum dia
sempat menpermainkan kerisnya,
pisau belati Pendekar Sutan telah
lebih dahulu tertancap di lambung
kirinya, mengenai jantungnya./
Beberapa jam kemudian Pendekar
Sutan ditangkap dan Datuak
Mantari Labih mati tidak beberapa
jam setelah tertikam. (hal: 13)

Kekerasan terjadi ketika Datuak Mantari Labih yang berselisih dengan Pendekar Sutan (ayah Zainuddin). Perselisihan dimulai ketika Pandekar Sutan berusaha melakukan pemberontakan kepada ninik mamaknya karena ia mengaggap bahwa ninik mamaknya telah berlaku tidak adil terhadapnya. Mengetahui bahwa hartanya disalah gunakan oleh Datuak 
Mantari Labih ninik mamaknya sendiri, Pendekar Sutan berusaha memberontak kekuasaan yang dimiliki oleh Datuak Mantari Labih. Dari kutipan di atas jelas tergambar kekerasan yang dilakukan Pendekar Sutan kepada Ninik mamaknya, namun ketika dianalisis lebih dalam, bentuk kekerasan ini dilakukan Pendekar Sutan untuk melindungi dirinya sendiri karena Datuak Mantari Labih telah lebih dahulu mengelurakan kerisnya yang mengancam keselamatan Pendekar Sutan. Bentuk kekerasan ini disadari oleh kedua belah pihak.

\section{b) Penindasan}

Penindasan ini hampir dilakukan oleh semua pemangku adat baik Ninik mamak dari Hayati, maupun ninik mamak dari Zainuddin. Penghinaan dan penindasan yang dilakukan oleh para pemangku adat tersebut terjadi baik secara langsung maupun tidak langsung terhadap korbannya. Penindasan pertama dilakuan oleh ninik mamak dari keluarga Hayati kepada Hayati dengan memperlakukan Hayati semena-mena dan menghina serta merendahkan derajat Hayati. Ninik mamak Hayati menganggap bahwa Hayati hanyalah seorang kemenakan dan dia juga masih telalu muda untuk memahami kehidupan khusunya asmara. Hal ini tertuang dalam kutipan berikut:

„Hai Hayati! Jangan engkau ukur
keadaan kampungmu dengan kitab-
kitab yang engkau baca. Pencintaan
hanyalah khayalan dongeng dalam
kitab saja. Kalau bertemu dengan
pergaulan hidup cela besar
namanya, merusak nama, merusak
ninik mamak, korang kampong,
rumah halaman./ ---- ,Hai upik,
baru kemarin kau memakan garam
dunia, kau belum tahu belit-
belitnya. Bukanlah kau sembarang
orang, bukan tampan Zainuddin itu
jodohmu. (hal:61)

Selain melakukan pengindasan dan penghinaan kepada Hayati, Datuak Dt juga melakukan penindasan dan penghinaan kepada Zainuddin. Ia memperlakukan Zainuddin dengan semena-mena dan menghina Zainuddin karena miskin, tidak memiliki gelar, dan tidak bersuku. Tidak hanya mengalami penindasan dari Datuak Dt ninik mamak Hayati, Zainuddin juga mengalami penindasan dan penginaan dari datuak dan bakonya sendiri Mande Jamilah dan datuak Panduka Emas. Bentuk penindasan ini adalah perlakuakan yang semena-mena oleh ninik mamaknya seperti tidak menganggapnya sebagai anak pisang, tidak memberikan tempat tinggal, gelar dan kekayaan pada Zainuddin. Hal ini tergambar dalam kutipan sebagai berikut:

Bertemu seorang tua di sebuah surau kecil, gelarnya Datuak Panduka Emas, dia hanya tercengang-cengang saja sambil berkata:,,Oh..rupanya si Amin ada juga meninggalkan anak di Mengkasar." Cuma sehingga itu pembicaraan orang tua itu, dan tidak ada tambahannya lagi. (hal :28)

Sebab kemanisan mulut bakonya kepadanya hanyalah lantaran belanja bulanan yang diberikannya dengan tetap, kiriman Mak Base dari Mengkasar. (hal: 32)

Penindasan dan penghinaan yang dilakukan oleh pemangku adat kepada Zainuddin dan Hayati dilakukan beberapa kali baik secara langsung maupun tidak. Pelaku penindasan dan penghinaan tersebut yaitu Datuak Dt (ninik mamak Hayati), Datuak Panduka Emas, dan Mande Jamilah (ninik mamak dan bako Zainuddin). Semua pemangku adat baik ninik mamak dari Hayati maupun Zainuddin seharusnya tidak melakukan tindakan penindasan dan penghinaan pada kemenakannya sendiri. Pemangku adat sebagai golongan kelas atas menghegemoni Zainuddin dan Hayati sebagai kelas bawah dengan melakukan penindasan dan penghinan.

\section{c) Paksaan}

Bentuk hegemoni yang ketiga dari jenis yang disadari yaitu adanya paksaan yang dilakukan satu tokoh kepada tokoh lain. Paksaan ini dapat berupa perkataan atau tindakan fisik baik secara langsung maupaun 
tidak langsung. Zainuddin dan Hayati menerima paksaan dari ninik mamamknya masing-masing, namun Zainuddin menerima tidak hanya dari ninik mamaknya saja namun dari ninik mamak Hayati. Paksaan yang terima Hayati dari ninik mamaknya berupa paksaan untuk menerima keputusan menikah dengan Aziz dan menolak Zainuddin. Hal ini tergambar dalam kutipan berikut:

Harus hal itu saya tanyai, karena di dalam adat kami di Minangkabau ini, kemenakan di bawah lindungan mamak. Hayati orang bersuku, berhindu, berkaum kerabat, bukan dia semabarang orang. (hal: 58)

Ya, kita habisi saja itu, kita bulatkan sekarang menerima Aziz, dan menolak permintaan Zainuddin. (hal: 114)

Paksaan yang diterima oleh Zainuddin dari ninik mamak, bakonya dan ninik mamak Hayati berupa paksaan untuk segera pergi tidak hanya meninggalkan Hayati namun pergi meninggalkan tanah kelahiran ayahnya sendiri. Dengan dalil adat dan kekuasaanya untuk melindungi Hayati, Datuak Dt telah dibutakan sehingga ia melakukan hegemoni kekuasaan berupa pada Zainuddin. Sedangkan untuk mempertahankan dan tidak ingin nama keluarga tercoreng oleh Zainuddin, ninik mamak dan bakonya pun turut memaksanya pergi dari Batipuh tanah kelahiran ayahnya sendiri. Hal ini tertuang dalam kutipan sebagai berikut:

Sebab itu, sangatlah saya minta kepadamu Zainnuddin, sudailah sekiranya engkau melepaskan Hayati dari dalam kenanganmu, dan berangkatlah dari negeri Batipuh yang kecil segera, untuk kemaslahatan Hayati./ --- Dengan sangat saya minta engkau berangkat saja dari sini untuk kemaslahatan Hayati yang engkau cintai. (hal: 59)

Bentuk hegemoni yang berupa paksaan baik secara langsung maupun tidak, dilakukan oleh pemangku adat sebagai kelas atas kepada Zainuddin dan Hayati sebagai kelas bawah. Hampir semua pemangku adat melakukan pemaksaan kepada Zainuddin dan Hayati dengan alasan menjaga kemenakan dan nama keluarga. Zainuddin dipaksa secara langsung untuk meninggalkan tanah kelahiran ayahnya sendiri. Paksaan juga diterima Hayati untuk mematuhi semua perintah dan pendapat dari ninik mamaknya. Sebagai kelas bawah Zainuddin dan Hayati tidak mampu melakukan tindakan atau perlawanan apapun.

\section{d) Perampasan}

Bentuk hegemoni berupa perampasan dialami oleh Hayati dan keluarga Zainuddin oleh masing-masing ninik mamaknya. Hayati mendapatkan perampasan atas hak asasi manusia, ia kehilangan hak-haknya dalam mengemukakan pendapat, aspirasi, dan menentukan sebuah pilihan. Ninik mamak Hayati secara langsung memiliki kekuasaan atas diri Hayati dan semua kekayaanya. Secara tidak langsung ninik mamaknya telah merampas haknya untuk besuara. Hal ini tertuang dalam kutipan sebagai berikut:

--- kita hanya bangsa perempuan yang tidak mempunyai hak apa-apa di dalam adat dan pergaulan. (hal: 39)

Mamak-mamak duduk berapat dikepala rumah yang ada di hilir, perempuan-perempuan duduk di dekat jalan ke dapur, mendengarkan buah mupakat dari jauh, ----- walaupun kadangkadang anaknya sendiri yang akan dipertunangkan atau dikawinkan. Dia hanya kelak akan diberi kata yang telah masak saja. (hal: 110)

Bebeda dengan perampasan yang dialami oleh Hayati, Zainuddin justru mendapatka perampasan yang lebih dari ninik mamak dan bakonya. Semua hak atas kekayaan Zainuddin, gelar, penidikan, status sosial dalam masyarakat serta hak asasi manusia telah dirampas darinya. Ninik mamaknya tidak memberikannya gelar, hak atas kekayaan milik ayahnya serta perlindungan dan penidikan kepada Zainuddin. Diskriminiasi yang dialami Zainuddin disebabkan karena ia memiliki ibu yang tidak berasal dari Minangkabu. Hal tersebut juga 
menyebabkan Zanuddin menjadi salah satu anggota dari kelas bawah yang hak-haknya selalu termarginalkan. Contoh salah satu kutipan yang menunjukan adanya hegemoni perampasan sebagai berikut:

Tidak dapat Zainuddin mengatakan dia orang Padang, tidak kuasa lidahnya menyebutnya dia orang Mianangkabau.Dan dia tidak berhak diberi gelar pustaka, sebab ia tidak bersuku. (hal: 27)

Bakoku sendiri tidak mengaku saya anak pisangnya, sebabrupanya ayahku tak mempunyai saudara yang karib. (hal: 41)

Para pemangku adat merasa memiliki hak untuk mengatur semua hak atas kekayaan, pendidikan, status dan gelar yang diberikan kepada kemenakannya. Kebanyakan pemangku adat dibutakan oleh sifat serakah hingga ia semena-mena dalam mengelola pemerintahan yang diberikan oleh adat kepadanya. Perampasan yang dilakukan pemangku adat kepada Zainuddin dan Hayati menyebabkan mereka kehilangan hak atas kekayaan, penidikan, status dan gelar dalam masyarakat.

\section{Hegemoni Kekuasaan yang Tidak} Disadaridalam Novel Tenggelamnya Kapal Van Der Wijck Karya Hamka

Hegemoni kekuasaan yang tidak disadari berupa adanya provokasi yang dilakukan oleh Datuk Dt kepada Zainuddin dan Hayati. Bentuk provokasi ini secara tidak langsung dan tidak sadari oleh korbannya. Bentuk hegemoni berupa Provokasi pertama dilakukan oleh Datuak Dt yang berusaha menghasut dengan meyakinkan Hayati bahwa Zainuddin bukan laki-laki yang pantas menjadi pendampingnya karena kemalangan nasib yang dialami Zainuddin, selain itu Zainuddin juga miskin dan tidak bersuku. Hal ini tertuang dalam kutipan berikut:

Bukanlah kau sembarang orang, bukan tampan Zainuddin itu jodohmu. Orang yang begitu tidak dapat untuk menggantungkan hidupmu, pemenung, penghiba hati, dan kadang- kadang panjang angan-angan di zaman sekarang haruslah suami menumpangkan hidup itu seorang yang tentu pencaharian, tentu asal-usul. Jika perkawinan yang demikian langsung, dan engkau boleh beranak, kemanakah anak itu akan berbako? (hal: 61)

Selain melakukan provokasi kepada kemenakannya Haytai, Datuak Dt juga melakukan propokasi kepada Zainuddin. Datuak Dt berusaha menghasut Zainuddin dengan menyatakan bahwa selama mengenal Zainuddin kini Hayati menjadi lebih kurus dan pemurung. Zainuddin telah merampas kebahagiaan dan kejehateraan Hayati. Hal ini tertuang dalam kutipan berikut:

,Ya, Tapi kasihan Hayati. Engku
sendiri tahu bagaimana dia
dipandang bunga dalam
pesukuannya. Dahulu dia lurus,
gembira, tetapi sekarang telah
pemenanung dan penghiba hati.
Hatinya telah rusak binasa setelah
berkenalan dengan engkau, dan
kalau diperuntukan agaknya
badannya kurus kering, dan kalau
dia terus binasa, bukanlah segenap
pesukuan dan perlindungan di
rumah gedang kehilangan mustika?
---- Sangatlah saya minta
kepadamu Zainuddin, sudilah
engkau melepaskan Hayati dari
dalam kenanganmu, dan
berangatlah dari Negeri Batipuh
yang kecil ini segera, untuk
kemaslahatan Hayati. (hal: 58-59)

Provokasi juga dilakukan oleh Datuak Garang pada datuk-datuk lain yang lebih muda dalam satu pesukuan Hayati. Tindakan tersebut dilakukan Datuak Garang untuk tetap mempertahankan kekuasaanya dan berusaha membentuk pola fikir baru kepada korbannya sehingga ia akan menuruti dan mematuhi perintah sang provokator. Datuak Garang sebagai datuak tertua dalam pesukuan Hayati berusaha melenggangkan kekuasaanya dengan mencoba agar pendapatnya selalu dituruti oleh semua datuak-datuak yang lain dalam pesukuan Hayati. Hal ini tergambar dalam kutipan berikut: 
Tak usah engkau berbicara. Rupanya engkau tidak mengerti kedudukan adat istiadat yang dipeturun penaik sejak dari ninik yang berdua, Dt. Perpatih nan Sebatang dan Dt. Ketemanggungan yang dibubutkan layu, yang dikisarkan mati. Meskipun ayahnya orang Batipuh, ibunya buka orang Minangkabau, mamaknya tidak tentu entah di mana, sukunya tidak ada: Tidak ada Perpatihnya, tidak ada Ketemanggungannya. Kalau dia kita terima menjadi sumai anak kemanakan kita, ke mana kemenakan kita hendak menelang iparnya, ke mana cucu kita berbako, rumit sekali soal ini. (hal: 113)

\section{DAFTAR PUSTAKA}

Anwar, Ahyar. 2010. Teori Sosial Sastra. Jakarta: Penerbit Ombak.

Brown, Trent. 2009. Gramsci and Hegemony. Links International Journal of Socialist Renewal. Jurnal. Diakses pada tanggal 4 Juni 2017 pukul 22:17

Damono, Sapardi Djoko.2010. Sosiologi Sastra Sebuah Pengantar Ringkasan. Jakarta: Pusat Pembinaan dan Pengembangan Bahasa Departemen Pendidikan dan Kebudayaan.

Pawestri, Shalikhatin. 2015. Hegemoni Kekuasaan dalam Novel Bibir Merah Karya Achmad Munif. Skripsi. Yogyakarta: Universitas Negeri Yogyakarta.

Pradopo, Rahmat Djoko.1994.PrinsipPrinsip Kritik Sastra Teori dan Penerapannya. Yogyakarta: Gadjah Mada University Press.

Puspitarini, Hening. 2014. Hegemoni Mitos Nyai Roro Kidul terhadap Kekuasaan Jawa dalam Novel Sang Nyai Karya Budi Sardjono. Skripsi. Semarang: Universitas Diponegoro.
Schwenz, Caroline Lee. 2014. Postcolonial Studies, Hegemony in Gramsci. Jurnal. https://scholarblogs.emory.edu/postcolonialstu dies /2014/06/20 / hegemony -in-gramsci/ Simon, Roger. 2004. Gagasan-Gagasan Politik Gramsci. Yogyakarta: INSIST. 